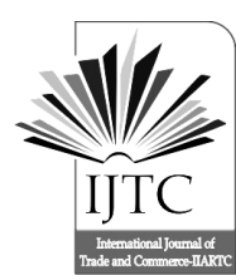

\title{
Inventory Control Policy for Imperfect Production Process on Various Demand and Fuzzy Nature: Latest Trend
}

\author{
Kamal Kumara, Ashok Kumar ${ }^{b^{*}}$, and Promilac \\ a Department of Mathematics, Baba Mastnath University, Rohtak, India \\ Email Id: kamalkumar4maths@gmail.com \\ ${ }^{b}$ Department of Mathematics, Meerut College, Meerut, India \\ Email Id:drakkashyap@hotmail.com \\ c Department of Mathematics, Baba Mastnath University, Rohtak, India \\ Email Id: promichahal2@gmail.com
}

\begin{abstract}
We learn about reviews of some inventory models for imperfect objects with various demands and fuzzy nature. During manufacturing, firstly, there produce a perfect object. We can say that production is an in-control state. But after some time it provides imperfect objects we can say that production change from in-control state to out of control state but there ignored of defective items. If the faulty items reached the customer, there are refunds and due to which extra cost suffered. To protect this, some researchers work on it. For this few of the researchers, take demands the triangular fuzzy number. Shortages are acceptable and partially backlogged. Demand is proportional to time. Production and repair rate are the function of demand, due to which repair rate and production both depend on the time. Some of the researchers take costs in fuzzy nature and the repair process used on imperfect objects. For discovering the imperfect quality, all objectives are screened before they sent for ingesting.

All defective objects are peddled at discount prices. The old idea of fuzziness of the fuzzy parameters was the same always, but due to the real-life human experience, the fuzziness activated to eliminate from the system over time. Mostly researcher firstly takes the non-fuzzy model (crisp model) and then fuzzification the model to find the decision. They fuzzification holding cost, shortage cost, and set up the price by the triangular and trapezoidal fuzzy numbers to find the overall price. The complete profit function is defuzzify by the graded mean integration method.
\end{abstract}

Key Words: Inventory, Imperfect, Triangular fuzzy, Trapezoidal, Partially backlogged, Graded mean integration method.

\author{
PAPER/ARTICLE INFO \\ RECEIVED ON: 20/02/2020 \\ ACCEPTED ON: 25/03/2020 \\ Reference to this paper \\ should be made as follows:

\section{Kamal Kumar, Ashok} \\ Kumar, and Promila (2020), \\ "Inventory Control Policy for \\ Imperfect Production Process \\ on Various Demand and \\ Fuzzy Nature: Latest Trend", \\ Int. J. of Trade and Commerce- \\ IIARTC, Vol. 9, No. 1, pp. \\ $148-158$
}




\section{INTRODUCTION}

Operations research is the assembly of present methods which are used to solve the problem face in the management of large system men, machine, goods, and money in the industry, business, and protection. Operations research is very crucial in the industry, management, production any other things. Inventory system plays a vital role to conserve and verifies product quality and electively challenges connections related to consumer goods. The inventory system is an essential condition that simplifies the smooth operation of occupational lairs in selling stores, storerooms, and production systems. In inventory, demand plays a vital role in maintaining it, and manufacturing planning is another phase that scholars are concerned about improving oversupplies and shortages of any object, the corporation carefully improves the manufacturing system. The manufacturing system has not to guarantee of full perfection; in real states, it also produces some imperfect quality object. For flawed production, there are many reasons like bad quality raw materials, uneducated labor, and machinery problem. Defective quality items are divided into two ways, like rework intelligence and scrap. Our aim of the research, develop the inventory models for flawed production processes with various demands in fuzzy nature.

Firstly, operations research was introduced during the Second World War. In the Second World War, the wrestling organization in England called a group of scientists to learn the strategic and wily difficulties linked to air.-and land in defense of the nation. At that time, the military resources were minimal; it is essential to decide the most operative consumption. The team of scientists allocating with an inquiry on the operations, the work of scientists, was termed as operations research in England. After winning the war, the group of scientists of England defines services research, according to which operations research is the art of winning battles without actually fighting the war. After completing the war, and winning the war by England, the method was attracted by the industrial management to solve their managerial type problems.

The first mathematical method in the field was developed by American mathematician Dantzig G.B. in 1947 and give this technique name the simplex method of linear programming. After which define operations research according to which operations research is the art of finding wrong answers to the problems to which otherwise worse answers are given. Usually, the fundamental inventory control model was firstly introduced by Harris in 1913. Harris announced an Economic Order Quantity model, which tells about how much have to be ordered and when to order would be placed accordingly that the total costs will be minimized. Also, we say that Harris gave the concept of value. He says that as the lot size increases, the carrying cost increases, and ordering cost decreases, and if the lot size decreases, the carrying cost also decreases, and ordering cost decreases. This ideal is used to find out the optimal order quantity that minimizes the inventory cost. In 1934 Harris model is extended by the Wilson and applied it widely and gave a method to find economic order quantity. This model played an essential role in the fundamental understanding of the requirement of an effective inventory system.

In 1933, the theory of imperfect was offered by Mrs. Joan Robinson in England and by E.H. Chamberlin in America. It is a fundamental market class where the different companies do work to control the price to least or more degree. It is being defined as the process in which some different buyers and sellers can affect price and production, where there is no full confession about the products and prices, where there are high blocks to entry and exit in the market.

Rosenblatt and Lee 1986 studied an economic production quantity model with imperfect quality items. 
Inventory Control Policy for Imperfect Production Process on Various Demand and Fuzzy Nature: Latest Trend Kamal Kumar, Ashok Kumar, and Promila

First of all, the concept of fuzzy given by the Zadeh in 1965. He tells about the fuzzy set. He says the fuzzy set is a collection of things with a field of scores of association, which is categorized by a characteristic function which gives to each object scores of membership going value between zero and one. Also, inclusion, union, intersection, complement, relation, convexity different types of these ideas in the setting of fuzzy sets are developed. In 1967 J.A. Goguen extended the fuzzy set, and he tells about the L fuzzy set. According to which, a fuzzy set is said to L fuzzy set if a fuzzy set is a set with a role of transitive partially order set.

\section{An Inventory Model for Imperfect Manufacturing Method with Various Demand RATE: LATEST TREND}

Inventory problems were developed many years ago. The review describes some of the important roles in this field. It consists of the inventory model for imperfect manufacturing processes for various demands. Most of the inventory models are under the assumption that demand is linear. But in real life state the demand for products like fashion goods, air seats decreases with time. So for the extensions of the models, many researchers studied the imperfect production process with various demands. Hartley and Whiten (1963) gave a superb account of the uses of inventory. Silver and Meal (1969) studied the realistic solution for time changing demand arrangement. Donaldson (1977) developed a mathematical model to find optimal order quantity when demand is changing linearly over the finite limits, and the shortage is not permissible. Mitra et al. (1984) studied a fundamental process for shifting the E.O.Q. model for the instance of changing linear demand. Rosenblatt and Lee (1986) investigated a model to learn the outcome of a process of imperfect production on the optimum production cycle time. Cheng (1991) proposed a model of Economic order quantity with production cost, which depends on demand and imperfect production processes. Chang (2004) developed a model for imperfect quantity under fuzzy environment. In this model, the imperfect fuzzy rate and fuzzy annual demand are included. The detached of this model is to determine the optimal lot size to maximize the total profit. Goyal et al. (2007) proposed a model to study the two choices of quality, for the imperfect quality objects which one is retail them to insignificant market as an only one group and minor price to that of original ones, or revise them at a specific cost and then custom them as original to fulfill demand rate. Panda et al. (2008) studied a model with a single period multi-product working group of stochastically imperfect substances. There is constant stochastic demand under economic and shortage limits are used. Parveen and Rao (2009) studied the optimal collection sizing quality for imperfect production processes with deterministic demand. Chauhan et al. (2011) developed an economic lot model for a manufacturing system that produces perfect and not perfect objects. A single period of several item volume springy manufacturing models is used for worsening objects. The demand rate is taken as random. Random, imperfect manufacturing is used. Deterioration is assumed to be known. Carrying cost is taken as linear. The shortage is permitted in inventory with partial backlogging. The technique is used to maximize profit. Singh et al. (2011) established a model with an exponential demand rate, and the production rate depends on demand under the inflation follow Weibull distribution. The shortage is allowed at the seller part only. Unfilled demand is not completely (partially) backlogged. Liu and Zheng(2012) learned a fuzzy E.O.Q. a model with imperfect class objects with a shortage. In the inspection, there are two types of error. This model is used to find the optimal solution. Shah et al. (2013) produced a combined manufacturing inventory model from the manufacturer and seller point of view when the demand for the product is growing with time. Aggarwal and Jain(2013) learned about a 
model for volume flexible industrial system. The production rate depends on stock. The system produces both qualities perfect and imperfect, for the perfect quality item demand is known or constant. For the imperfect quality object, demand is a function of discount offered at the selling price. Patel et. al. (2013) gave a model for Weibull deteriorating items in inventory. Demand is a function of time under permitted delay in payments, and price rises. Holding cost is a linear function. The shortage is allowed and fully backlogged. Chakrabarty et al. (2014) gave a model for inventory manufacture with the setup costs. In this model, the price rises, and the time value of money assumed to be an imperfect production process. The demand rate depends on advertisement cost and selling price. The model provides a logical solution to maximize the total profit function. Shah et al. (2014) gave an economic production model with an imperfect production process with time declining demand form. The impartial of this function is to maximize the total profit in a single item effect. Widianto et al. (2014) developed joined model involving single-Vendor and single-buyer system. The manufacturing process is imperfect, and the demand rate is deterministic for buyers. The model produces an optimum solution for possible joined the total annual cost of the "vendor and buyer." Kumar and Goswami(2015) gave a model of Economic production quantity. In this model, we studied the passion-demand rate and the units that have an unbroken rate of worsening. Changing the demand rate and the worsening rate have a major effect on the decision variables and the total cost of inventory. Ritha et al. (2016) formatted an economic production model to fulfill the demand in the right proportion and at the right time. Majumder et al. (2016) gave a model for economic production for breakable items. Demand is a linear function of time. Manufacturing rate and carrying costs are depending on time, and unit manufacturing is a function of manufacturing reliability and manufacturing rate. Ordering cost is not completely dependent on the production rate. A shortage is allowed. Uthayakumar and Kumar (2016) developed a single buyer united production inventory with stochastic demand for the imperfect production process. The lead time is a linear function of the lot size. Patel (2017) provided a deterministic inventory model of imperfect quality. For an economic order quantity, all items received order is perfect quality is not always fulfilled. Some of the items can be defective. Also, there are some other assumptions that as soon as items are received, payment is made. The demand rate is a function of time and price. Saget al. (2017) produced an inventory model that involves a single buyer and a single vendor. Its inventory was achieved by the buyer periodically, and products are ordered from the vendor to fulfill the demand rate where the annual demand and set up cost are in fuzzy nature. The process of the vendor is imperfect. The purpose of this model is to find the optimum value for the review period. Astanjin and Sajadieh(2017) gave a united production model with price dependent demand for the damaged items. This model is developed to find the optimal solution. Kurdhi et al. (2017) made a collaborative vendor buyer production model for imperfect quality items with inspection error and stochastic demand. This model is used to determine the least inventory total cost as compare to separated inventory. Saha and Chakrabarti(2018) learned about two-echelon supply chain models for breakable items in imperfect manufacturing procedures involving single manufacturers. In this single retailer, the customer demand for the retailer depends on the advertisement and displayed a stock level of the retailer. This model is developed to find the cost function. Shah et al. (2018) developed a model with quadratic demand. The objective of this model is to optimize the total cost of the inventory system concerning screening time cycle time and investment for the protection technology. Khedlekarand Tiwari(2019) gave a model to discuss the effect of concession prices on demand and profit in the falling market. The process is 
Inventory Control Policy for Imperfect Production Process on Various Demand and Fuzzy Nature: Latest Trend Kamal Kumar, Ashok Kumar, and Promila

an imperfect production process. Demand is taken to be price sensitive. Demand is a negative power function of marketing price. This model is developed to determine the optimum expected average profit, optimal marketing price, concession rate, backorder level, and lot size.

\section{An Inventory Model for the IMPerfect Production Process in FuZzy EnVironment: LATEST TREND}

Zadeh (1965) proposed a fuzzy set, which is a collection of things with a field of scores of association. Such a set is categorized by a characteristic function that gives each thing a score of membership ranging the value between zero and one. Inclusion, union, intersection, complement, relation, convexity, various types of these concepts in the situation of fuzzy sets are developed. Mizumoto and Tanaka (1976) gave the arithmetical arrangements of fuzzy scores with the operations of intersection $\mathrm{i}$, union $\mathrm{m}$, and complement $-\mathrm{c}$, which is well-defined by the addition opinion, convex fuzzy scores form Belgiansemiring. Normal convex fuzzy scores form a distribution law under $\mathrm{i}$ and $\mathrm{m}$. The arithmetical properties of fuzzy scores with the operations +,and $\backslash$ which are a little different from $i$ and $m$. Vujosevic et al. (1996) studied the Economic order quantity (E.O.Q.) formula in the occurrence of roughly valued parameters. Carrying cost and set up costs, which are not exactly well-known and are regularly carried by language terms such as: "Carrying cost is around of value $C_{c}$, or: "set up cost is about value $C_{o}$ or more." These are assumed to be fuzzy numbers, defined on a restricted interval on the axis of real numbers. Roy and Mati (1997) proposed a fuzzy Economic order quantity model with partial storage ability. The demand rate depends on unit price and the ordering cost proportional to the quantity produced. Buckley and Feuring(2000) studied about to solve the problem of fuzzy first-order initial value problem. We find the solutions with fuzzy initial value problems for linear and nonlinear fuzzy first-order differential equations. Chang(2004) gave the inventory problem for imperfect quality item Fully screening process is performed when order is the arrival, and the imperfect class objects are traded as an only one group at a reduced price, previous to getting the next shipment. This model is developed to find the optimum order lot size to exploit the total profit. This model contains the imperfect fuzzy rate and fuzzy annual demand. For determining an estimation of gross profit per unit time in the fuzzy logic, the signed distance method is used. Chen et al. (2005) learned about a model for fuzzy E.P.Q. with imperfect objects that can be refurbished. Also, we study a fuzzy occasion cost, trapezoidal fuzzy costs, and amounts into the old-style manufacture stock model. Maiti et al. (2006) gave a stock held model for the multi items. There are two types of storage services with trailer, price, and demand dependent displayed inventory in a fuzzy nature. In this model, buying cost, investment amount, and warehouse capacity are rough. Chen et al. (2007) studied a model for imperfect objects which model is Fuzzy Economic Production Quantity (F.E.P.Q.) model. The imperfect objects can be sold at a reduced price. In this model, costs and amounts are trapezoidal fuzzy numbers. Bera et al. (2009) studied a manufacturing inventory model for fading objects with imperfect production process above a finite time limit. The demand rate is proportional to selling cost and mark-up to the manufacturing cost. This ideal is developed to exploit gross profit, which contains backorder cost, carrying cost, worsening cost, manufacturing cost, ordering cost, and selling cost. The demand rate is defined in fuzzy nature. Triangular fuzzy numbers are used for fuzziness. Hu et al. (2010) developed an economy making run-time difficulty. The imperfect making processes and acceptable shortages are used. In the past time, making process changes in a fuzzy random 
variable and construct a model for a fuzzy random total cost per unit time. The belief theory and "ranking method" is used to change the fuzzy random model into a nonfuzzy model. Ameli et al. (2011) study about the stock held model to find the setup policy for imperfect objects with a fuzzy environment. The objective function is fuzzy. The signed distance method is used to estimate the current value of total profit during the preparation time horizon. Nagoorgani and Ponnalagu (2012) gave a division operation of Triangular Intuitionistic Fuzzy number (T.I.F.N.) using $\alpha, \beta-$ cut, and a scoring function to rank T.I.F.N.s. An exactness function of defuzzify T.I.F.N. is also announced. This model is used to determine the solution of Intuitionistic Fuzzy Linear Programming. Liu and Zheng(2012) developed a fuzzy economic order quantity engineering problem for imperfect quality and with shortages. There are two kinds of errors for screening the well-known lot and a defective screening process. The portion of defectives in the ordered lot is considered to be a "fuzzy number." Singh et al. (2012) studied a model for two-store house manufacturing for defective objects. Manufacture rate is a linear combination of on-hand inventory and demand. Demand depends on time. The manufacturing rate is a function of demand, and Shortages is permitted and not completely backlogged. The backlogging rate depends on time. For conservation facilities, the worsening rate depends on time in its storehouse and Weibull distribution worsening in the rented storehouse. Carrying cost in rent storehouse is more than in own storehouse. We proposed a model for fuzzing costs of the model as fuzzy triangular numbers. Mahata(2013) studied an inventory model. The objects received are defective. The shortage is backordering, and also the nature of the shortage is fuzzy. A fully screening process is performed for arrival orders. This model is proposed to find the optimum lot size and the optimum shortage quantity to maximize the total annual profit. There are several kinds of fuzzy models where the first model with fuzzy incomplete rate and a second model with fuzzy incomplete rate and fuzzy yearly demand rate. To find the gross profit per unit time in the fuzzy nature ranked method is used. Ritha and S.S.A. (2013) developed an outdated economic production/order quantity (EPQ/EOQ) model. There are take some assumptions to form a closed-form solution for the optimum lot size in a manufacturing facility. The model is settled to determine the optimal order lot size to maximize the total profit by employing the type of fuzzy triangular numbers. There are few kinds of fuzzy inventory models in the first model, the fuzzy reliability level is used, and the second model with fuzzy reliability and fuzzy economic manufacturing quantity (E.P.Q.) is obtainable. The ranked method is used to determine the approximation of gross profit per unit time in the fuzzy nature and then derive the equivalent optimum lot size. Manaa et al. (2014) investigated a model for inventory with an imperfect production process. The Product reliability and reworking of defective items in the three-layer supply chain in fuzzy rough nature. Mondal et al. (2014) studied "homogeneous ordinary differential equation in a fuzzy environment of first order where the initial condition of the differential equation of first order" is a triangular fuzzy number. Kazemi and Olugu (2015) proposed a model for the incomplete class object in a fuzzy nature. The wisdom occurs in the locale of the fuzzy parameters. In this model, we proposed a complete profit function with a fuzzy parameter. For making it fuzzify the parameter, a Triangular fuzzy number is used, and wisdom bend is combined into the fuzzy model to the justification for the knowledge in fuzziness. Kurdhi et al. (2015) gave a model for fuzzy joint vendor-buyer manufacturing inventory with deal level restraint. Vendors use the imperfect production process. Ordering cost 
Inventory Control Policy for Imperfect Production Process on Various Demand and Fuzzy Nature: Latest Trend Kamal Kumar, Ashok Kumar, and Promila

and cycle time can be decreased financing costs. Cycle time demand has a normal distribution and distribution-free. This model is developed to optimize the lot size, cycle time, rearrange point, ordering cost, and several consignments in one making cycle, reserved on a service level, such that to minimize the total combined cost. We use a minimax distribution free process to find the optimum solution in case of free distribution. Kumar and Goswami(2015) learned about the result of the unit manufacture time on the best lot size for the inexact and indefinite defective manufacturing procedure. Shortages are allowed and not completely backlogged. We propose the fuzzy chance of manufacturing procedure changing from a 'good' state to a 'not good' state and reliability of the poor quality of making objects. The passed the time when the procedure change is assumed to be fuzzy. Fuzzy expectation and ranked method are used to change the fuzzy arbitrary price function into a nonfuzzy function. De and Mahata(2016) studied the traditional backorder economic order quantity inventory model in a cloudy fuzzy environment. For this, firstly, we take the crisp model, then fuzzification the model to find a result under the cloudy fuzzy, and demand is tracked by its real-world application. Shekarian et al. (2016) developed a model for an economic order quantity for imperfect quality objects, Which depends on two different carrying costs and knowledge concerns. The fuzzy technique is used to solving an Economic order quantity problem. Both parameter and decision variables are fuzzy triangular numbers. Fuzzy arithmetic operations are used to find the complete profit per unit time. Khatua and Maity (2016) gave a multi-objective production control inventory problem. There are two objective functions where the first objective function is for economic profit in maximizing form, and the second objective function is used to calculating the amount of polluting gases in minimizing form in the fuzzy-rough environment. Inaccurate problem is converted into a similar crisp multi-objective problem by using fuzzy- rough mathematics. Rajalaksmi and Rosario(2017) formatted a fuzzy inventory model. The shortage is allowed, and it is completely backlogged. Costs like carrying cost, backorder cost, and ordering cost are in fuzzy nature using triangular, trapezoidal, pentagonal fuzzy numbers to find the fuzzy total cost. The signed distance method is used for defuzzification to approximate the total cost. Kumar (2018) gave a model for an inventory with defective quality objects in fuzzy nature. Shortages are permitted and also backlogged. For classifying the objects with poor quality, all objects are partitioned before they are guided for ingesting, and all defective quality objects are sold at bargain-basement prices. Demand will be expected exactly, because demand rate change with many indeterminate and worrying market events, it is considered to be a type-2 fuzzy variable. Jain et al. (2018) studied about joined inventory model for defective production procedures. Demand depends on time in an inflationary environment. The production rate is changing with demand. And therefore it also depends on time. The reconstruction rate is a function of time. The cost orders, production, reproduction, checkup, and carrying costs are in fuzzy nature. The main impartial of this joint with the stock held model is to find the optimum value of total cost. Liu et al. (2019) developed the supply chain returning policy and quantity discount coordination for imperfect quality objects. In this model, we consider that the demand rate is a triangular fuzzy number. The fuzzy set is used to learning the producer's quantity discount and the vender's coordination of coming back procedure. The ranked method is used to find the optimum order quantity in the supply chain, and the optimization theory is used to maximize the contributors' profits. De et al. (2019) learned about an E.O.Q. a model with defective quality objects. The screening process is 
Inventory Control Policy for Imperfect Production Process on Various Demand and Fuzzy Nature: Latest Trend

Kamal Kumar, Ashok Kumar, and Promila

performed. To cancel out the matters of non-random doubts of demand in the occupational state cloudy fuzzy method to be used.

\section{CONCLUSION}

In this paper, we studied the reviews of inventory models for imperfect objects. Thus, we observed that mostly production rate and repair rate dependent on time and demand. The parameter is not equally loyal to the improvement of the earnings curve. Superior of perfect order quantity and exact cycle time can transform the entire decision of an inventory process. All the costs like set up costs, holding value, selling value are in a fuzzy environment. Keeping cost discloses that less holding cost authorizations to store more items in the shop. With increased holding costs, the selling price of items also increased.

\section{REFERENCE}

[1]. Aggarwal K. K and Jain D (2013), The Optimal Production - Run Time for A StockDependent Imperfect Production Process, Yugoslav Journal of Operation Research, Vol. 23(1), pp. 111-127.

[2]. Ameli M, Mirzazadeh A and Shirazi M.A (2011), Economic Order Quantity Monday with Imperfect Items Under Fuzzy Inflationary Conditions, Trends in Applied Science Research, Vol.6(3), pp. 294-303

[3]. Astanjin M. B and Sajadieh M. S(2017), Integrated Production- Inventory Model with Price-Dependent Demand, Imperfect Quality and Investment in Quality and Inspection, AUT Journal of Modelling and Simulation, Vol. 49(1), pp. 43-56.

[4]. Bera U.K, Mahaptra N.K and Maiti M (2009), An Imperfect Fuzzy Production -Inventory Model Over A Finite-Time Horizon Under the Effect of Learning, International Journal of Mathematics In Operations Research, Vol.1 (3) pp.351-371.

[5]. Bukley J.J and Feuring T (2000), Fuzzy Differential Equations, Fuzzy Sets and Systems, Vol.110 (1), pp. 43-54.

[6]. Chakrabarty R, Roy T and Chaudhuri K.S. (2014), A Production- Inventory Model with J.I.T. Set Up Cost Incorporating Inflation and Time Value of Money in An Imperfect Production Process, International Journal of Modern Engineering Research, Vol. 4(2), pp.57-65.

[7]. Chang H. C (2004), An Application of Fuzzy Set Theory to The E.O.Q. Model with Imperfect Quality Items, International Journal of Production Economics, Vol. 31(12), pp. $2079-2092$.

[8]. Chauhan A, Kumar M and Kumar P. (2011), Economic Production Lot Size Model with Stochastic Demand and Shortage Partial Backlogging Rate Under Imperfect Quality Items, International Journal of Advanced Science And Technology, Vol. 31, pp.1-22.

[9]. Chen S.H, Wang S.T and Chang S.M. (2005), Optimization of Fuzzy Production Inventory Model with Repairable Defective Products Under Crisp or Fuzzy Production Quantity, International Journal of Operations Research, Vol. 2, pp. 31-37.

[10]. Chen S.H, Wang S.T and Chang S.M. (2007), Fuzzy Economic Production Quantity Model for Items with Imperfect Quality, International Journal of Innovative Computing, Information and Control, Vol. 3, pp. 85-95.

[11]. Cheng T.C.E (1991), An Economic Order Quantity With Demand Dependent Unit Production Cost And Imperfect Production Process, I.I.E. Transactions, Vol. 23(1), pp. 23-28.

[12]. De S.K and Mahata G.M (2016), Decision of a Fuzzy Inventory with Fuzzy Backorder Model Under Cloudy Fuzzy Demand Rate, International Journal of Applied and computational mathematics, Vol.3. 
Inventory Control Policy for Imperfect Production Process on Various Demand and Fuzzy Nature: Latest Trend

Kamal Kumar, Ashok Kumar, and Promila

[13]. De S.K and Mahata G.M (2019), A cloudy fuzzy economic order quantity model for imperfect- quality items with allowable proportionate discounts, Journal of Industrial Engineering International.

[14]. Donaldson W.A.(1977), Inventory Replenishment Policy for A linear Trend in Demand- An Analytical Solution, Operational Research Quarterly, Vol. 28, pp.663-670.

[15]. Goyal S.K., Konstantras and Papachristos (2007), Economic Ordering Policy for An Item with Imperfect Quality Subject to in House Inspection, International Journal of System Science, Vol. 38, pp.473-482.

[16]. Hartley G and Whiten (1963). Analysis of inventory system. Management Science, vol. 20, pp. 464-471.

[17]. Hu J.S, Xu R.Q, Zheng H and Ping Ji.Y (2010), Supply Chain coordination for Fuzzy Random Newsboy Problem with Imperfect Quality, International Journal Approximate Reasoning, Vol.51(7), pp.771-784.

[18]. Jain S, Tiwari S, Barron L.E.C, Shaikh A.A and Singh S.R (2018), A Fuzzy Imperfect Production and Repair Inventory Model with Time-Dependent Demand, Production and Repair Rates Under Inflationary Condition, RAIRO-Operations Research, Vol.52, pp.217-239.

[19]. Kezememi N. and Olugu U.E. (2015),Development of a Fuzzy Economic Order Quantity Model for Imperfect Quantity Items Using the Learning Effect on Fuzzy Parameters, Journal of Intelligent \&Fuzzy Systems, Vol.28, pp. 2377-2389.

[20]. Khedlekar U.K and Tiwari R. K(2019), Decision Making in Discount Pricing Policy for Imperfect Production System, Yugoslav Journal of Operations Research, Vol. 29(2), pp. 273-293.

[21]. Khutua A and Maity K (2016), Research on the Relationship Between Economic Profit and Environmental Pollution of Imperfect Production Inventory Control Problem in FuzzyRough Environment, International Journal of Engineering Applied Sciences and Technology, Vol. 1(9), pp.162-168.

[22]. Kumar R.S (2018), Modelling a type-2 fuzzy inventory system considering items with imperfect quality and shortage backlogging, Sådhanå, pp.1-10.

[23]. Kumar R.S and Goswami A. (2015), E.P.Q. A model with learning consideration, imperfect production, and partial backlogging in fuzzy random environment, International Journal of Systems Science, Vol.46 (8), pp.1486-1497.

[24]. Kurdhi N.A, Nurhayti R.A, Wiyano S.B, Handajani S.S and Martini T.S (2017), A collaborative Vendor -Buyer Production-Inventory Systems With Imperfect Quality Items, Inspection Errors, And, Stochastic Demand Under Budget Capacity Constraint: A Karush Kuhn-Tucker Conditions Approach, I.O.P. Conf. series: Materials Science And Engineering, Vol. 166, pp.1-13.

[25]. Kurdhi N.A, Lestari S.M.A and Sasanti Y. (2015), A Fuzzy Collaborative Chain Inventory Model with Controllable Set Up Cost and Service Level Constraint for Imperfect Items, International Journal of Applied Management Science, Vol.7, pp. 93-122.

[26]. Liu J. and Zheng H. (2012), Fuzzy Economic Order Quantity Model with Imperfect Items, Shortage and Inspection Errors, System Engineering Procedia, Vol. 4, pp.282-289.

[27]. Liu S, Gao J and Xu Z (2019), Fuzzy Supply Chain Coordination Mechanism with Imperfect Quality Items, Technological and Economic Development of Economy, Vol.25 (2), pp.239-257.

[28]. Mahata G.C (2013), Application of Fuzzy Sets Theory in an E.O.Q. Model for Items with Imperfect Quality and Shortage Backordering, International Journal of Services and Operations Management, Vol. 14, pp. 466-490. 
Inventory Control Policy for Imperfect Production Process on Various Demand and Fuzzy Nature: Latest Trend

Kamal Kumar, Ashok Kumar, and Promila

[29]. Maiti M.K, Maiti M (2006), Fuzzy Inventory Model with Two Warehouses Under Possibility Constraints, Fuzzy Sets and Systems, Vol.157 (1), pp.52-73.

[30]. Majumder P, Bera U. K and Maiti M (2016), A Multi-Item E.P.Q. Model with Imperfect Production Process for Time-Varying Demand with Shortages, Hacettepe Journal of Mathematics and Statistics, Vol. 45(3), pp. 929-955.

[31]. Manna A.K, Dey J.K and Mondal S.K (2014), Three Layer Supply Chain in an Imperfect Production Inventory model with two Shortage Facilities Under Fuzzy Environment, Journal of Uncertainty Analysis and Applications, Vol.2, pp.1-31.

[32]. Mitra A, Cox J. F. and Jesse R. R (1984), A Note on Determining Order Quantities with A Linear Trend in Demand, Journal of the Operational Research Society, Vol. 39, pp.687-692.

[33]. Mizumato M and Tanaka K (1976), Some Properties of Fuzzy Sets of Type 2, Information and Control, Vol. 31, pp. 312-340.

[34]. Mondal S.P and Roy T.K (2014), First Order Homogeneous Ordinary Differential Equation with Initial Value as Triangular Intuitionistic Fuzzy Number, Journal of Uncertainty in Mathematics Science, Vol.2014, pp.1-17.

[35]. Nagoorgani A. and Ponnalagu K. (2012), A New Approach on Solving Intuitionistic Fuzzy Linear Programming Problem, Applied Mathematical Sciences, Vol. 6, pp.3467-3474.

[36]. Panda D, Kar S, and Maiti M (2008), A single period Inventory model with imperfect production and stochastic demand under chance and imprecise constraints, European Journal of Operational Research, Vol. 688(1), pp. 121-139.

[37]. Parveen M. and Rao T.V.V.L.N (2009), Optimal Batch Sizing, Quality Improvement, and Rework for an Imperfect Production System with Inspection and Restoration, European Journal of Industrial Engineering, Vol. 3, pp.305-335.

[38]. Patel S.S (2017), Inventory Model with Different Deterioration Rates For Imperfect Quality Items and Inflation Considering Price and Time-Dependent Demand Under Permissible Delay in Payments, International Journal of Latest Technology In Engineering Management $\mathcal{E}$ Applied Science, Vol. 6(8), pp.1-9.

[39]. Patel S. S and Patel R(2013), An Inventory Model for Weibull Deteriorating Item with Linear Demand, Shortages Under Permissible Delay in Payments and Inflation, International Journal of Mathematics and Statistics Invention, Vol. 1(1), pp. 22-30.

[40]. Rajalakshmi R.M and Rosario G.M (2017), A Fuzzy Inventory Model with Allowable Shortage Using Different Fuzzy Numbers, International Journal of Computational and Applied Mathematics, Vol. 12, pp.227-240.

[41]. Ritha W and Priya I. V (2016), Environmentally Responsible E.P.Q. Model with Rework Process of Detective Items, International Journal of Computer Science and Mobile Computing, Vol. 5(9), pp. 193-204.

[42]. Ritha W and S.S.A. A.S (2013), Optimization of Fuzzy Inventory Model with Imperfect Production lot sizing and Marketing Planning Problem, Elixir Applied Math, Vol. 55, pp.12838-12841.

[43]. Rosenblatt M. j and Lee H.L (1986), Economic Production Cycles with Imperfect Production Processes, I.I.E. Transactions, Vol.18 (1), pp. 48-55.

[44]. Roy T.K and Mati M (1997), A Fuzzy E.O.Q. Model with Demand-Dependent Unit Cost Under Limited Storage Capacity, European Journal of Operations Research, Vol.99(2), pp.425432. 
Inventory Control Policy for Imperfect Production Process on Various Demand and Fuzzy Nature: Latest Trend

Kamal Kumar, Ashok Kumar, and Promila

[45]. Saga R. S, Jauhari W. A and Laksoo P. W (2017), A Periodic Review Integrated Inventory Model with Controllable Setup Cost, Imperfect Items, and Inspection Errors Under Service Level Constraint, I.O.P. Conf. series: Materials Science and Engineering, Vol. 273, pp. 1-7.

[46]. Saha S and Chakrabarti T(2018), Two-Echelon Supply Chain Model for Deteriorating Items in An Imperfect Production System with Advertisement and Stock Dependent Demand Under Trade Credit, International Journal of Supply and Operations Management, Vol. 5(3), pp. 207-217.

[47]. Shah N. H and Shah B. J. (2014), E.P.Q. Model for Time Declining with Imperfect Production Process Under Inflationary Conditions and Reliability, International Journal of Operations Research, Vol. 11(3), pp. 91-99.

[48]. Shah N. H, Gor A.S and Jhaveri C. A(2013), An integrated Production-Inventory Model With Imperfect Production Process in Buoyant Market, International Journal of Advanced Engineering Applications, Vol. 2(3), pp. 56-64.

[49]. Shah N. H, Patel D. G, and Shah B. G (2015), E.P.Q. Model for Imperfect Production Processes With Rework and Random Preventive Machine Time for Deteriorating Items and Trended Demand, Yugoslav journal of operations Research, Vol. 25(3), pp. 425-443.

[50]. Shah N.H, Chaudhari U, and Jani M.Y (2018), Optimum inventory control for a defective quality item with maximum lifetime under Quadratic demand and Preservation Technology Investment, International Journal of Applied Engineering Research, Vol.13, pp.12475-12485.

[51]. Shekarian E, Ezutah, Olugu E.U, Hanim S, Abdul-Rashid, and Kazemi. N (2016), An economic order quantity model considering different holding costs for imperfect quality items subject to fuzziness and learning, Journal of Intelligent $\mathcal{E}$ Fuzzy Systems, Vol. 30, pp.2985-2997.

[52]. Silver E. A. And Meal H. C. (1969). A Simple Modification of The E.O.Q. for the Case of Varying Demand Rate, Production of Inventory Management, Vol.10(4), pp. 52-65.

[53]. Singh C. and Singh S.R. (2011), Imperfect Production Process with Exponential Demand Rate, Weibull Deterioration Under Inflation, International Journal of Operational Research, Vol. 12(4), pp. 430-445.

[54]. Singh S.R, Jain S and Pareek S (2012), A Warehouse Imperfect Fuzzified Production Model with Shortages under Inflationary Conditions, Hindawi Publishing Corporation Advances in Decision Sciences, Vol. 2012, pp.1-16.

[55]. Uthayakumar R and Kumar M. G (2016), Single Vendor-Buyer Integrated Inventory System for Imperfect Production with Variable Lead Time, Operations Research And Applications: An International Journal, Vol. 3(1), pp. 1-15.

[56]. Vujosevic M, Petrovic D, and Petrovic, R (1996), E.O.Q. Formula when Inventory Cost is Fuzzy, International Journal of Production Economics, Vol.45, pp. 499-504.

[57]. Widianto I.P, Jauhari W.A and Rosyidi C.N (2014), Cooperative Vendor-Buyer Inventory Model With Imperfect Quality and Inspection Errors, International Multiconference of Engineers And Computer Scientists, Vol. 2, pp. 978-988.

[58]. Zadeh L.A (1965) Fuzzy Sets, Information and Control, Vol. 8, pp. 338-353 